\title{
Em busca do sentido produzido no discurso literário: uma possibilidade de análise pela Teoria Argumentativa da Polifonia
}

Looking for produced meaning on literary discourse: a possible analysis by the Argumentative Theory of Polyphony

Lauro Gomes ${ }^{1}$

Bárbara Luzia Covatti Malcorra ${ }^{2}$ Pontifícia Universidade Católica do Rio Grande do Sul, Escola de Humanidades,
Programa de Pós-Graduação em Letras. Porto Alegre, RS, Brasil.

Doutorando em Letras (área de concentração: Linguistica) pela Pontifícia Universidade Católica do CNPq.

(ib https://orcid. org/0000-0002-1302-2693 E-mail: lauro.gomes.001@acad.pucrs.br

Doutoranda em Letras (área de concentração: Linguistica) pela Pontificia Universidade Catolica ( Bolsista integral do CNPq

org/0000-0001-5710-7130
RESUMO: Este artigo objetiva descrever e explicar o sentido expresso no discurso literário, com base na metodologia proposta pela fase mais atual da Teoria da Argumentação na Língua, a saber: a Teoria Argumentativa da Polifonia. A partir da descrição do conteúdo argumentativo do discurso literário Os ninguéns, de Eduardo Galeano, são identificadas a atitude discursiva do locutor e a Pessoa Enunciativa. Quer-se mostrar como se dá a articulação das entidades abstratas da língua (pela Teoria dos Blocos Semânticos) com as entidades concretas verificáveis no uso linguístico efetuado pelo locutor (pela Teoria da Polifonia), uma vez que - considerando-se a indissociabilidade entre langue e parole, do ponto de vista fenomenológico - segundo o que têm defendido Marion Carel e Oswald Ducrot, em seus trabalhos atuais, faz-se necessário estudar a constituição semântica do discurso de modo a relacionar, efetivamente, o ponto de vista da fala com o ponto de vista da língua. Por fim, acredita-se chegar ao sentido global do discurso por intermédio da seguinte unidade tripla: (1) pela atitude discursiva; (2) pela Pessoa Enunciativa e (3) pelo conteúdo argumentativo. Palavras-chave: Argumentação; Polifonia; Sentido; Discurso literário.

ABSTRACT: This paper aims to describe and explain the meaning expressed on literary discourse, based on the methodology proposed by the most current stage of the Theory of Argumentation within Language, namely: the Argumentative Theory of Polyphony. From the description of the argumentative content of the literary discourse Os ninguéns, by Eduardo Galeano, it searches to identify the speaker discursive attitude and the Enunciative Person. It pursuits to demonstrate the articulation of the language system entities (by the Theory of Semantic Blocks) with the verifiable concrete entities in the linguistic use effected by the speaker (by the Theory of Polyphony), since - considering the inseparability between langue and parole from the phenomenological point of view - according to what Marion Carel e Oswald Ducrot have defended in their current papers, it is necessary to study the semantic constitution of the discourse in order to effectively relate the point of view of the speech with the point of view of the language. Therefore, it is believed to achieve the discourse global meaning through the following triple unit: (1) by the discursive attitude; (2) by the Enunciative Person e (3) by the argumentative content.

Keywords: Argumentation; Polyphony; Meaning; Literary discourse. 


\section{Introdução}

$\checkmark$ ste artigo busca descrever e explicar o sentido de um discurso literário à luz de princípios e conceitos propostos pela fase mais atual da Teoria da Argumentação na Língua (ANL), a saber: a Teoria Argumentativa da Polifonia (TAP), desenvolvida atualmente por Marion Carel e Oswald Ducrot na Escola de Altos Estudos em Ciências Sociais de Paris. Pelo fato de a TAP ser uma teoria que integra a Teoria da Polifonia (DUCROT, 1984) à Teoria dos Blocos Semânticos (CAREL, 1995), muitas modificações em conceitos desses dois momentos anteriores da ANL têm-se feito com o objetivo de desenvolver uma teoria da colocação do conteúdo em discurso.

Ao buscar descrever o conteúdo argumentativo dos enunciados e identificar a atitude discursiva do locutor e a voz da Pessoa Enunciativa - segundo o método proposto pela fase mais atual da Semântica Argumentativa - apreende-se a unidade de discurso, que explicita não apenas a significação, mas também o sentido das entidades linguísticas de modo mais amplo e profundo. Por essa razão - embora em desenvolvimento - a TAP inaugura uma nova fase nos estudos semânticos francófonos, em que os sentidos produzidos no discurso literário também podem ser explicados a partir dos princípios da linguística autônoma inaugurada por Ferdinand de Saussure.

Para tanto, na primeira seção deste artigo, apresentam-se os conceitos que fundam e desenvolvem - até a postulação da TAP - a Teoria da Polifonia em Linguística; na segunda, resgatam-se alguns dos conceitos e princípios fundamentais para a descrição do conteúdo argumentativo, segundo a Teoria dos Blocos Semânticos (TBS); na terceira, apresentam-se os principais conceitos da TAP, necessários para a análise do corpus, realizada na quarta seção. Por fim, explicitam-se as considerações finais, em que se sistematizam algumas pistas a serem seguidas pelo linguista para descrever e explicar o sentido produzido no discurso literário, considerando a relação entre a significação das entidades linguísticas e a sua enunciação pelo locutor.

\section{Relação entre o sistema linguístico e o seu uso no discurso}

\subsection{Teoria da Polifonia: um desenvolvimento da enunciação na linguagem}

A noção de polifonia tem-se feito presente na ANL desde os primeiros trabalhos de Oswald Ducrot a respeito da linguagem. Apresentada pela primeira vez em Les mots du discours (1980), e melhor desenvolvida em Le dire et le dit (1984)¹, em La polifonía (1985) e em Polifonía y Argumentación (1990), ela introduz um novo olhar para o sentido, uma vez que rejeita a ideia de um único sujeito no enunciado - cuja concepção, salvo algumas observações de Charles Bally (1965), era predominante na linguística da época. A partir daí, Ducrot (1984) constrói uma teoria polifônica da enunciação, segundo a qual o sentido de um enunciado é o resultado das diferentes vozes nele presentes. Essa concepção de semântica, sobre a qual Ducrot (1984) desenvolve seu trabalho, consiste em considerar o sentido como uma descrição da sua enunciação. Mais precisamente, segundo Anscombre e Ducrot (1983, p. 36), a enunciação diz respeito à atividade linguageira exercida por aquele que fala no momento em que fala. É, pois, um acontecimento histórico que não se reproduz duas vezes de maneira idêntica.

Com base nisso, para poder descrever essas imagens que o enunciado veicula em sua enunciação, Ducrot (1984) estabelece uma rigorosa distinção entre frase e enunciado, conceitos fundamentais que perpassam toda a Teoria da Argumentação na Língua. Segundo o autor, a frase é uma

${ }_{1}^{1}$ O livro $O$ dizer e o dito foi traduzido para a Língua Portuguesa e publicado, no Brasil, em 1987. 
entidade teórica e, por isso, não pertencente ao domínio do observável, enquanto o enunciado é uma realidade empírica, "manifestação particular, como a ocorrência hic et nunc de uma frase" (DUCROT, 1987, p. 164, grifo do autor). Dessa forma, conforme destaca Ducrot (1985), em La Polifonía, o enunciado está submetido à enunciação, uma vez que é uma realidade que não pode repetir-se, pois está situada em um momento específico do tempo e do espaço. Além desses dois conceitos, o autor também denomina texto o conjunto de frases e discurso a sequência de enunciados inter-relacionados.

Uma vez consideradas as naturezas distintas de frase e enunciado relembrando que a primeira é abstrata, pertencente ao sistema, enquanto a segunda é concreta, relativa à realização da língua - atribuem-se a esses conceitos valores semânticos também distintos. Dessa forma, a significação está para a frase, posto que diz respeito a um conjunto de instruções que especificam as "manobras" que deverão ser realizadas por quem interpretará o enunciado. Já o sentido está para a realização da frase, isto é, para o enunciado, uma vez que é no uso da língua que se constrói o sentido, a partir das orientações dadas pela significação. Afinal, conforme elucida Ducrot (1985, p. 23, tradução nossa), “A significação da frase não constitui em si mesma uma mensagem compreensível; ela consiste simplesmente em indicações sobre o que é necessário fazer e o que se tem de buscar na situação para reconstruir o sentido do enunciado"2. Em outras palavras, pode-se dizer que o sentido das entidades concretas decorre de sua situação de emprego e, em especial, da relação entre as significações das entidades abstratas da língua.

Em virtude de o sentido de um enunciado ser, então, uma espécie de resultado do debate criado entre diferentes vozes nele presentes, cumpre 2 La significación de la oración no constituye en si misma un mensaje comprensible; ella consiste
simplemente en indicaciones sobre lo que es necesario hacer y lo que hay que buscar en la situación para reconstruir el sentido del enunciado. (DUCROT, 1985, p. 23). explicitar quais são essas vozes e quais os elementos que, segundo Ducrot (1990), constituem o sentido de um enunciado. No primeiro capítulo de Polifonía y Argumentación, intitulado La polifonía en lingüística, Ducrot (1990, p. 15-29) analisa a noção de sujeito falante a partir de três funções muito diferentes: a de Sujeito Empírico, a de Locutor e a de Enunciador.

O Sujeito Empírico é o autor efetivo do enunciado, ser de carne e osso, e que, portanto, não é de interesse do semanticista. O Locutor, por sua vez, segundo o que consta em $O$ dizer $e$ o dito, “[...] é um ser do discurso, pertencente ao sentido do enunciado, e resultante desta descrição que o enunciado dá de sua enunciação" (DUCROT, 1987, p. 195). Trata-se, pois, do responsável pela enunciação no próprio enunciado, em cuja entidade concreta está marcado por meio de expressões como "eu", "meu", "me" e também, em certa medida, por "aqui" e "agora". Já os Enunciadores são descritos como as "[...] origens dos diferentes pontos de vista que se apresentam no enunciado"3 (DUCROT, 1990, p. 20, tradução nossa).

Com base nessas funções, na segunda conferência de Polifonía y Argumentación, Ducrot (1990, p. 65-80) acrescenta que o sentido de um enunciado consiste em três elementos, a saber: 1) a apresentação dos pontos de vista dos diferentes enunciadores; 2) a indicação da posição do locutor em relação aos enunciadores (identificação, aprovação ou oposição) e 3) a assimilação dessas atitudes ao próprio locutor ou a outros enunciadores. Essas atitudes do locutor são geralmente exemplificadas pelo semanticista por meio da asserção, da negação, da pressuposição, dos enunciados com mas e também pelos discursos humorísticos e irônicos.

Feitas essas explicitações, é importante chamar a atenção para a função de Enunciador, visto que ela tem uma estreita relação com o conceito de

${ }^{3}[. .$.$] orígenes de los diferentes puntos de vista que se presentan en el enunciado.$ 
topos, desenvolvido por Jean-Claude Anscombre e Oswald Ducrot na Forma Standard Ampliada da Teoria da Argumentação na Língua. Nas palavras de Ducrot (1990, p. 163-164, grifo do autor, tradução nossa), "O 'ponto de vista' de cada enunciador consiste em evocar, em convocar a propósito de um estado de coisas, um princípio argumentativo (o que chamo, retomando o termo aristotélico, um topos)"4. Note-se, então, que, nessa fase específica da ANL, Anscombre e Ducrot consideraram um elemento extralinguístico na constituição do sentido, uma vez que, por meio dos topoi - princípios comuns argumentativos na coletividade em que o discurso é utilizado - chega-se a um argumento que justifica determinada conclusão.

Por essa razão, a noção de Enunciador vem sendo atualmente reexaminada por Marion Carel e Oswald Ducrot. Em artigo traduzido e publicado no Brasil sob o título Atualização da Polifonia $^{5}$, pode-se compreender que o Enunciador era a única noção ainda considerada epistemologicamente inadequada em relação aos princípios da ANL e, em especial, aos postulados da TBS. Como bem destacam Carel e Ducrot (2010) no referido texto, se os enunciadores fossem vistos como fontes ou origens dos conteúdos - como a Teoria da Polifonia pressupunha até então - seria infringida a radical concepção antirreferencialista da TBS, segundo a qual os pontos de vista são constituídos unicamente por encadeamentos argumentativos (DUCROT; CAREL, 2008, p. 7). Dessa forma, já que a TBS recusa integrar ao sentido elementos informativos, os referidos autores optam por não mais utilizar a noção de Enunciador e a substituem por Pessoa Enunciativa, como se pode verificar na seção 2.3.

\footnotetext{
${ }^{4}$ El "punto de vista" de cada enunciador consiste en evocar, en convocar a propósito de un estado de cosas, un princípio argumentativo (lo que llamo, retomando el término aristotélico, un topos).

5 Artigo publicado originalmente, na revista Langue française (2009/4; n. 164), sob o título Mise au Artigo publicado originalmente, na revista Langue française (2009/4, n. 164), sob o título Mise au point sur la polyphonie. Link: <https://www.cairn.info/revue-langue-francaise-2009-4-page-33.htm>.
Acesso em: 12 set. 2017 .
}

\subsection{Teoria dos Blocos Semânticos: uma teoria do conteúdo argumentativo}

Postulada por Marion Carel (1992), a Teoria dos Blocos Semânticos radicaliza e desenvolve as ideias que fundam a Teoria da Argumentação na Língua, criada por Anscombre e Ducrot (1983). Ao rejeitar a noção extralinguística de topos e substituí-la pela noção intralinguística de interdependência semântica entre predicados da língua, a TBS reintroduz a coerência estruturalista que - conforme explica Ducrot (1999) - tinha se perdido durante o desenvolvimento da Teoria dos Topoi.

Pelo fato de a ANL ser uma semântica linguística autônoma, o pensamento saussuriano a fundamenta em todas as suas fases. Na TBS, em especial, as noções de relação e de valor linguístico ganham ainda maior evidência. Desse modo, buscando desenvolver a tese de que a argumentação é um fenômeno linguístico profundo, ou seja, inerente à língua (langue), Carel e Ducrot (2005) defendem que o sentido de uma entidade linguística qualquer - seja uma palavra, um enunciado ou todo um discurso - constituise por um conjunto de encadeamentos argumentativos que essa entidade evoca. Chega-se, por conseguinte, a uma concepção nova de sentido.

Dessa definição de sentido decorrem as noções de interdependência semântica e de bloco semântico. Nos termos da TBS, a interdependência semântica é definida como uma relação indecomponível entre dois predicados de um encadeamento argumentativo. Note-se que, quando, por um lado, unem-se dois predicados por intermédio de portanto $\left(\operatorname{donc}^{6}\right)$ - a exemplo de (1) Trabalha, portanto tem sucesso - tem-se um encadeamento normativo. Por outro lado, quando se unem dois predicados por meio de

6 Abreviado como DC, o donc representa uma série de conectores de mesma natureza, a exemplo de então, porque, visto que, pois, etc. 
no entanto (pourtant ${ }^{7}$ ) - a exemplo de (2) Trabalha, no entanto não tem sucesso - tem-se um encadeamento transgressivo. Segundo Carel e Ducrot (2005, p. 13, tradução nossa), “[...] o sentido de uma entidade linguística não está constituído por coisas, fatos, propriedades, crenças psicológicas, nem ideias"8. Por esse motivo, não existe, no interior do encadeamento argumentativo, nenhum tipo de passagem, ao fim da qual um predicado (considerado o argumento) transmite sua veracidade ao outro (considerado a conclusão). Ou seja, está vetada, aqui, qualquer forma de relação entre sentido e exterioridade linguística.

Já o bloco semântico é uma entidade única indecomponível subjacente a todo encadeamento argumentativo normativo ou transgressivo. Por exemplo, o bloco semântico que realiza o compartilhamento do sistema da língua nos encadeamentos (1) e (2) pode ser expresso por um enunciado como "quem trabalha tem sucesso". Isso posto, pode-se ainda perguntar por que o sentido é entendido, para a TBS, como um conjunto de encadeamentos argumentativos. $\mathrm{O}$ que melhor parece esclarecer essa definição de sentido é a noção de quadrado argumentativo, já que - ao explicitar os aspectos argumentativos $^{9}$ do bloco semântico - o quadrado argumentativo traz à luz as relações discursivas autorizadas pela significação das entidades da língua.

A seguir, apresentam-se dois quadrados argumentativos que formalizam o mesmo bloco semântico. Confiram-se:

\footnotetext{
${ }_{7}$ Abreviado como PT, o pourtant representa uma série de outros conectores de mesma natureza, a exemplo de mas, porém, entretanto, todavia, contudo, embora, ainda que, mesmo assim, etc.

8 [...] el sentido de una entidad lingüistica no está constituido por cosas, hechos, propiedades, creencias psicológicas, ni ideas. (CAREL; DUCROT, 2005, p. 13).

9 De acordo com Carel e Ducrot (2005), ao conjunto de encadeamentos argumentativos convencionou-se chamar aspecto argumentativo. Um aspecto normativo como PERTO DC FÁCIL CHEGAR contém, entre outros, encadeamentos como (1) O hotel está perto da Universidade, portanto é fácil chegar; (2) Meu dormitório está perto do teu, portanto é fácil chegar; (3) A Catedral está perto da Faculdade, portanto é fácil chegar.
}

Figura 1 - Quadrado argumentativo que formaliza o bloco semântico doxal

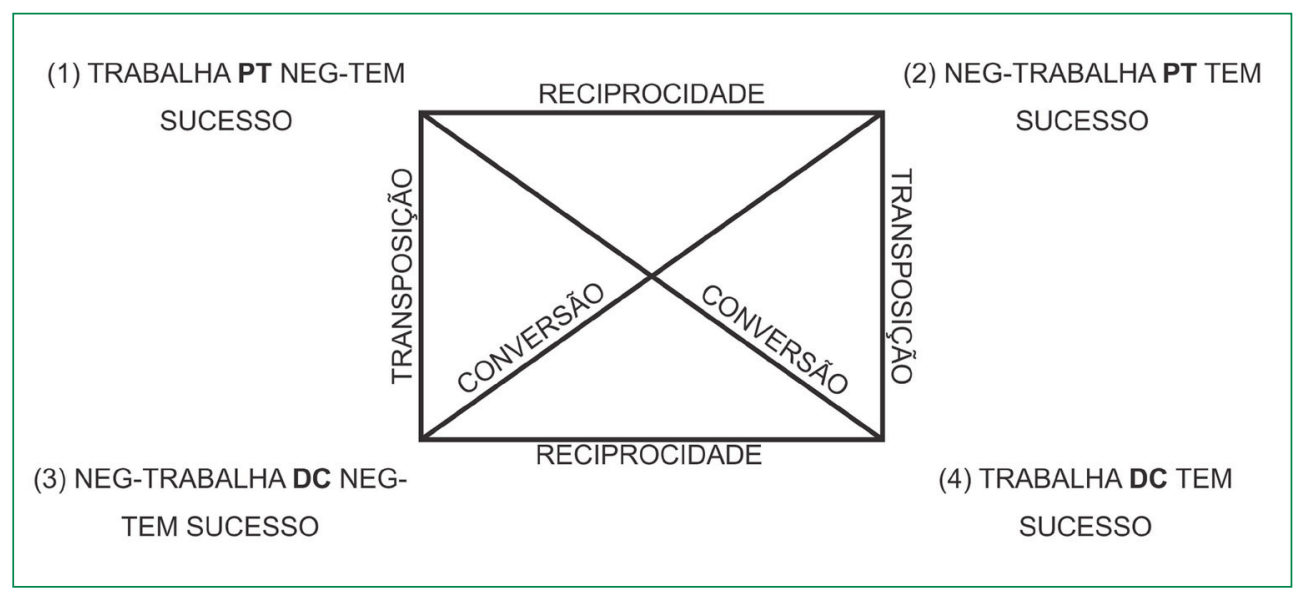

Fonte: Figura fundamentada em Carel e Ducrot (2005).

Da relação estabelecida entre os predicados A: TRABALHAR e B: TER SUCESSO depreendem-se, notadamente, quatro aspectos doxais - cada um dos quais poderia manifestar-se numa série de encadeamentos. Daí o fato de o sentido ser definido, nesta fase da ANL, como um "conjunto de encadeamentos argumentativos".

Como se pode visualizar na Figura 1, as relações discursivas que se estabelecem entre os aspectos transgressivos (1) e (2) e entre os aspectos normativos (3) e (4) são de reciprocidade; entre (1)-(3) e (2)-(4) são relações de transposição; e, na diagonal do quadrado, entre (1)-(4) e (2)-(3), são relações de conversão. Esse mesmo fenômeno linguístico-discursivo pode ser observado no quadrado argumentativo paradoxal. 
Figura 2 - Quadrado argumentativo que formaliza o bloco semântico paradoxal

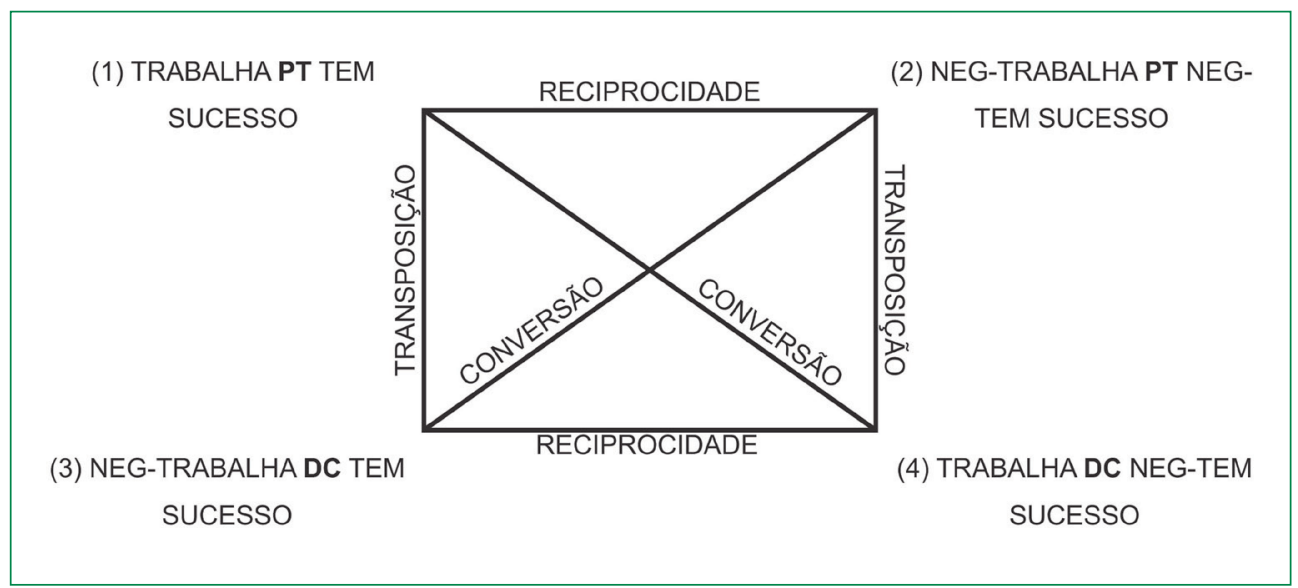

Fonte: Figura fundamentada em Carel e Ducrot (2005).

Do mesmo modo, mas desta vez numa relação paradoxal, esse segundo quadrado argumentativo explicita os quatro aspectos que são, nos termos de Carel (2013), um "prolongamento", isto é, um desenvolvimento semântico dos aspectos doxais. Essas relações são, na maioria das vezes, consideradas "sem sentido" - quando usadas com imprecisão e descuido na linguagem ordinária - mas absolutamente possíveis de "fazerem sentido" numa linguagem poética, por exemplo, cujas normas de relação entre predicados são estabelecidas mais pela combinatória do discurso do que pela estrutura semântico-argumentativa do sistema linguístico.

Notadamente, o referido conjunto de encadeamentos - que constitui o sentido de enunciados e discursos - deve ser evocado a partir das normas que governam a relação semântica entre as entidades linguísticas. Para citar um último exemplo, um enunciado como Seu pecadinho foi julgado um caso de forca, por exemplo, permite evocar, segundo Carel (2012), um encadeamento transgressivo como Cometeu um pequeno delito, no entanto sofreu uma grande punição, ao qual se pode associar um aspecto argumentativo transgressivo que constitui uma argumentação interna (AI) ${ }^{10}$ de injustiça, a saber: PEQUENO DELITO PT GRANDE PUNIÇÃO. Tem-se, nesse caso, um julgamento argumentativo completo ou, em outros termos, um motivo argumentativo.

A TBS é, em vista disso, uma teoria do "conteúdo argumentativo". Essa versão da ANL, de acordo com Carel e Ducrot (2005), busca explicar a língua pelo discurso - o qual não está baseado nem nas coisas nem no pensamento. Como a argumentação é descrita sem fazer alusão às propriedades do mundo, o que somente intervém na construção do conteúdo argumentativo são os conectores DC (donc $\rightarrow$ portanto) e PT (pourtant $\rightarrow$ no entanto), e o caráter positivo e o negativo dos predicados.

\subsection{Teoria Argumentativa da Polifonia: uma teoria da colocação do conteúdo em discurso}

Inscrita na família das teorias linguísticas que têm a enunciação por objeto, a TAP é uma teoria que surge - no domínio da Semântica Argumentativa - com o propósito de articular polifonia e argumentação. Em entrevista publicada pela editora francesa Lambert-Lucas, sob o título Les risques du discours, Oswald Ducrot afirma:

0 grande problema é tornar compatível a teoria da polifonia e a teoria da argumentação. Essas duas teorias existem lado a lado, mas não são verdadeiramente postas em relação. Aquilo de que Marion Carel e eu nos

${ }^{10}$ Segundo explica Carel (2011), a argumentação interna (AI) de uma entidade linguística $E$ - seja um verbo, um substantivo, um adjetivo ou todo um enunciado - é constituída por um certo número de de um aos quais pertencem os encadeamentos que parafraseiam a entidade E. Assim, a significação de cujo encadeamento que o realiza pode ser representado por Era perigoso, portanto Pedro prestou
atenção. 
ocupamos atualmente é da colocação em relação dessas duas teorias: trata-se de mostrar como os pontos de vista apresentados numa visão polifônica do sentido podem ser considerados como argumentativos e não representacionais (DUCROT, 2013, p. 34, tradução nossa) ${ }^{11}$.

Notadamente, referindo-se a princípios e conceitos de que se trata neste artigo ao longo das seções 1.1 e 1.2, Ducrot deixa claro que, por meio de um desenvolvimento da noção de ponto de vista (representada pela função Enunciador, conforme foi possível verificar na seção 1.1), a fase atual da Semântica Argumentativa (TAP) articula a Teoria da Polifonia com a Teoria dos Blocos Semânticos. Logo, a partir de uma correção de cunho metodológico, acredita-se também haver um aprofundamento epistemológico da teoria, na medida em que fica finalmente vetada qualquer possibilidade de relação e/ou de introdução de elementos extralinguísticos na semântica, sobretudo quando o sentido é descrito e explicado com base na perspectiva polifônica (cf. DUCROT, 1984).

Por essa razão, a TAP substitui a noção de Enunciador pela de Pessoa Enunciativa, cuja noção - não tendo nenhum parentesco com o ser empírico do mundo extralinguístico - nada mais é do que um tom ${ }^{12}$ capaz de explicitar as maneiras pelas quais o conteúdo é apresentado no discurso pelo locutor. Nesse sentido, distintamente de teorias enunciativas clássicas, como a de Émile Benveniste, a TAP postula a existência de cinco Pessoas Enunciativas, a saber: o próprio Locutor (aquele que fala), o TU (aquele a quem se fala), o IL ([Ele, em Português] cuja Pessoa representa uma voz distanciada do

${ }^{11}$ Le grand problème, c'est de rendre compatible la théorie de la polyphonie et la théorie de l'argumentation. Ces deux théories existent côte à côte, mais ne sont pas vraiment mises en relation. Ce dont Marion Carel et moi nous occupons actuellement c'est de la mise en relation de ces deux théories: il s'agit de montrer comment les points de vue présentés dans une vue polyphonique du sens peuvent être considérés comme argumentatifs et non représentationnels. (DUCROT, 2013, p. 34).

${ }^{12}$ Segundo explica Carel (2011, p. 293, grifo da autora, tradução nossa), "Eu definirei, então, as Pessoas como sendo 'tons' (no sentido em que se pode exigir de alguém que deixe de falar nesse tom), mais ou menos autoritários". ausente e que, embora sem autoridade, pode falar em muitos enunciados), o ON ([-se $e^{13}$, em Português] cuja Pessoa foi inspirada em Berrendonner (1981) e que, ainda na sua origem, é entendida como uma voz da opinião pública, ou seja, uma voz da coletividade, também chamada de doxa) e o MUNDO (Pessoa que permite ao locutor tomar um tom factual e que se manifesta quando o locutor se desresponsabiliza pelo conteúdo).

Segundo explica Carel (2011, p. 295), todo discurso comunica unidades triplas - chamadas unidades de discurso - constituídas pela atitude discursiva do locutor (posto, acordado e excluído), pela Pessoa Enunciativa (L, TU, IL, ON, MUNDO) e pelo conteúdo (argumentativo). No texto Polifonia e argumentação, Carel (2010) propõe um método próprio de análise discursiva à luz da referida unidade de discurso. Entre parênteses, explicitam-se, respectivamente, a atitude discursiva, a Pessoa e o conteúdo. Assim, o locutor de um enunciado como "Faz bastante bom tempo", por exemplo, põe o conteúdo [Faz bom tempo] e fala com a voz do Locutor. A unidade de discurso é, então, metodologicamente representada da seguinte forma: (posto, L, [Faz bom tempo]).

A Pessoa TU pode ser exemplificada, de acordo com Carel (2011, p. 337), por um discurso como "Tu tens razão de dizer que ela não é má", visto que o locutor introduz a unidade (posto, TU, [ela não é má]). Já a Pessoa do ausente pode ser explicitada por meio de um enunciado do tipo de "Parece que vai fazer bom tempo", cuja unidade introduzida pelo locutor é (posto, IL, [vai fazer bom tempo]). Seguindo esse mesmo método, pode-se exemplificar a Pessoa ON pelo seguinte enunciado apresentado por Carel (2010, p. 16): "Ele deve ter parado de fumar recentemente". Esse enunciado funcionaria,

${ }^{13}$ Nos trabalhos de Semântica Argumentativa traduzidos para o Português do Brasil, o $O N$ tem sido geralmente entendido como -se. É preciso salientar, porém, que essa pessoa gramatical específica da língua francesa também pode ser empregada como a gente ou como a primeira pessoa do plural (nós) em traduções livres para o Português. 
segundo a autora, como uma hipótese explicativa para o comportamento de nervosismo e inquietação de alguém. Tratar-se-ia, então, de uma relação linguístico-discursiva estabelecida por uma opinião pública segundo a qual quando se deixa de fumar, fica-se geralmente nervoso. Assim, pode-se dizer que o locutor responsável pelo referido enunciado hipotético introduz a unidade (acordado, ON, [deve ter parado de fumar recentemente]). Por fim, para exemplificar a Pessoa MUNDO, pode-se dizer que o locutor de um enunciado como "Maria diz que vai fazer bom tempo", por exemplo, põe o conteúdo [Maria tem a propriedade de dizer que $q$ ] e fala com a voz do MUNDO. Em vista disso, a unidade de discurso é metodologicamente representada da seguinte forma: (posto, MUNDO, [Maria tem a propriedade de dizer que $q]$ ).

Note-se que os dois primeiros elementos da unidade vêm de uma concepção polifônica do sentido e o terceiro elemento - o conteúdo - tem origem na concepção argumentativa (cf. a TBS). Por isso, conforme explica Carel (2012, p. 12-13), a TBS é considerada uma "teoria do conteúdo", isto é, disso que é posto em discurso, e a TAP é uma teoria da "colocação desse conteúdo" em discurso. Por estar em desenvolvimento - com a observação de novos fenômenos na linguagem - têm-se denominado também função textual a atitude discursiva do locutor e modo de aparição do conteúdo os outros dois elementos da unidade de discurso. Por não constituir objetivo deste artigo e por questões de delimitação, essas duas noções não são aprofundadas neste trabalho.

Apesar disso, faz-se relevante salientar que a colocação em discurso tem sido descrita a partir destas duas indicações: uma relativa à função textual do conteúdo - que permite identificar, inclusive, certa hierarquia existente entre os conteúdos, pelo seu grau de relevância no discurso (diz-se ser posto no plano da frente ou ser posto no plano de trás) - e a outra relativa ao modo de aparição desse conteúdo. Em enunciados como "Eu acho esse sermão monótono" e "Esse sermão é monótono", por exemplo, - embora os conteúdos tenham a mesma função textual, isto é, o mesmo papel discursivo - pode-se perceber que o locutor investe-se na enunciação do primeiro enunciado, mas não na enunciação do segundo. A partir daí nasce toda a análise linguístico-discursiva pela TAP.

\section{Análise semântico-argumentativa de discurso literário}

Buscando atender aos propósitos deste artigo, elegeu-se como corpus de análise o miniconto Os ninguéns, extraído do Livro dos abraços, de Eduardo Galeano. A metodologia de análise, aqui estabelecida, segue os princípios propostos pela TAP, a saber: (1) primeiramente é feita a descrição do conteúdo argumentativo do discurso. No entanto, ao invés de explicitá-lo pela segmentação dos enunciados, conforme faz a TAP, foram evocados os encadeamentos argumentativos dos enunciados e a eles associados seus respectivos aspectos argumentativos do bloco semântico, à luz dos princípios da $\mathrm{TBS}^{14}$; (2) a seguir, buscando explicar o sentido que vem da enunciação, identifica-se a atitude do locutor; (3) por fim, seguindo os princípios dessa semântica que considera o sentido polifônico, identifica-se a Pessoa responsável pelo conteúdo argumentativo.

Pelo fato de o discurso estar claramente organizado sob dois planos textuais, optou-se por dividi-lo em dois trechos. O primeiro é constituído por quatro unidades de discurso e o segundo, por cinco. Observe-se a análise que segue:

${ }^{14}$ Neste estudo, optou-se por descrever o conteúdo por meio de encadeamentos argumentativos e pela explicitação dos aspectos a eles associados, não apenas por se acreditar - de momento - na possibilidade de se chegar desse modo a uma explicação mais completa do sentido, mas também pelos limites impostos pelo gênero artigo científico. 
Trecho 1

As pulgas sonham com comprar um cão, e os ninguéns com deixar a pobreza, que em algum dia mágico a sorte chova de repente, que chova a boa sorte a cântaros; mas a boa sorte não chove ontem, nem hoje, nem amanhã, nem nunca, nem uma chuvinha cai do céu da boa sorte, por mais que os ninguéns a chamem e mesmo que a mão esquerda coce, ou se levantem com o pé direito, ou comecem o ano mudando de vassoura.

GALEANO, Eduardo. O livro dos abraços. 2. ed. Porto Alegre: L\&PM, 2012.

Esse primeiro trecho, constituído por uma série de enunciados, permite evocar inicialmente a unidade de discurso (posto, MUNDO, [ser pulga, portanto sonhar com comprar um cão]) a cujo conteúdo argumentativo normativo pode-se associar o aspecto NEG-SER NINGUÉM DC ADQUIRIR FUTILIDADES. A palavra plena pulga está numa relação opositiva com ser ninguém. Ou seja, nesse contexto linguístico-discursivo, ser pulga significa ser alguém. Essa palavra opõe-se, no interior do discurso, às seguintes relações normativas [ser ninguém, portanto sonhar com deixar a pobreza], [ser ninguém, portanto sonhar que a sorte chova de repente] e [ser ninguém, portanto sonhar que a boa sorte chova a cântaros], que se associam, respectivamente, ao aspecto argumentativo normativo SER NINGUÉM DC SONHAR COM SER ALGUÉM. Notadamente, os outros dois elementos do tripé que integra a unidade de discurso com o conteúdo argumentativo explicitado pelos referidos encadeamentos são a atitude discursiva do locutor (posto) e a Pessoa Enunciativa (MUNDO).

Na sequência, evoca-se a unidade de discurso (posto, MUNDO, [sonha com chuva de boa sorte, no entanto a sorte nunca chove], [sonha com chuva de boa sorte, no entanto não cai chuvinha do céu da boa sorte]), cujo aspecto associado aos referidos encadeamentos argumentativos pode ser SONHAR COM SER ALGUÉM PT NUNCA SER. Na continuação, pode-se evocar a unidade de discurso (acordado, ON, [chama, coça a mão esquerda, levanta-se com o pé direito e começa o ano mudando de vassoura, no entanto não cai chuvinha do céu da boa sorte]). Note-se que há, não apenas um acréscimo semântico expresso pelo primeiro segmento do referido encadeamento, mas também uma permanência do sentido expresso pelo segundo segmento do aspecto explicitado anteriormente. Em vista disso, o aspecto argumentativo que melhor explicita a significação subjacente ao sentido do encadeamento da unidade de discurso acima apresentada pode ser PRATICAR SUPERSTIÇÕES PT NUNCA SER ALGUÉM.

\section{Trecho 2}

Os ninguéns: os filhos de ninguém, os donos de nada.

Os ninguéns: os nenhuns, correndo soltos, morrendo a vida, fodidos e mal pagos:

Que não são, embora sejam.

Que não falam idiomas, falam dialetos.

Que não praticam religiões, praticam superstições;

Que não fazem arte, fazem artesanato.

Que não são seres humanos, são recursos humanos.

Que não têm cultura, têm folclore.

Que não têm cara, têm braços.

Que não têm nome, têm número.

Que não aparecem na história universal, aparecem nas páginas policiais da imprensa local. Os ninguéns, que custam menos do que a bala que os mata.

GALEANO, Eduardo. O livro dos abraços. 2. ed. Porto Alegre: L\&PM, 2012.

A primeira unidade de discurso comunicada pelo locutor nesse segundo trecho é (posto, MUNDO, [ser ninguém, portanto ser filho de ninguém e dono de nada]), cujo aspecto associado ao encadeamento que expressa o conteúdo argumentativo da referida unidade é SER NINGUÉM DC NEG-TER FAMÍLIA E BENS. Posteriormente, evoca-se a unidade de discurso (posto, MUNDO, [ser ninguém, portanto ser nenhum correndo solto, morrendo a vida, fodido e mal pago]), a cujo conteúdo argumentativo normativo pode-se associar o aspecto SER NINGUÉM DC ESPERAR A MORTE. 
Acrescentando conteúdo semântico-argumentativo ao discurso, é interessante observar o enunciado Que não são, embora sejam, do qual se pode evocar a unidade de discurso (posto, MUNDO, [ser pessoa, no entanto ser ninguém]), a cujo conteúdo argumentativo transgressivo se pode associar o aspecto SER PT NEG-SER.

Interessante observar alguns aspectos de forma e de conteúdo dos enunciados que seguem. Introduzidos pelo pronome relativo que - tanto os enunciados positivos quanto os negativos - podem ser condensados no segundo segmento dos sete seguintes encadeamentos normativos: [ser ninguém, portanto não falar idioma, falar dialeto], [ser ninguém, portanto não praticar religiões, praticar superstições], [ser ninguém, portanto não fazer arte, fazer artesanato], [ser ninguém, portanto não ser humano, ser recurso humano], [ser ninguém, portanto não ter cultura, ter folclore], [ser ninguém, portanto não ter nome, ter número], [ser ninguém, portanto não aparecer na história universal, aparecer nas páginas policiais da imprensa local], aos quais se pode associar o aspecto argumentativo único SER NINGUÉM DC NEG-SER RECONHECIDO. Os outros dois elementos do tripé que integra a unidade de discurso com o conteúdo argumentativo explicitado pelos referidos encadeamentos são a atitude discursiva do locutor (posto) e a Pessoa Enunciativa (MUNDO).

Para finalizar a descrição semântico-argumentativa do discurso em foco, evoca-se a unidade de discurso (posto, MUNDO, [ser ninguém, portanto custar menos do que a bala da morte]), cujo aspecto associado ao conteúdo argumentativo da referida unidade é SER NINGUÉM DC NEG-TER VALOR.

\section{Conclusão}

Descrever e explicar o sentido na linguagem nunca foi tarefa fácil para os linguistas. Muitas teorias foram e continuam sendo desenvolvidas com esses propósitos, mas realmente poucas parecem atingir o alcance vislumbrado pela ANL. Desenvolvida com base nos princípios saussurianos e a partir deles, essa teoria busca, no interior do sistema linguístico, as alusões à enunciação do locutor e postula - pela Teoria da Polifonia - que o "sentido de um enunciado", por exemplo, nada mais é do que a representação que o próprio enunciado dá de sua enunciação; e, segundo a TBS, o sentido é um conjunto de encadeamentos argumentativos (normativos e transgressivos).

Atualmente, com o objetivo de mostrar de modo ainda mais explicativo como se dá a passagem da língua para o discurso, isto é, da significação para o sentido, Marion Carel e Oswald Ducrot desenvolvem a TAP, que modifica e integra à TBS os princípios e conceitos enunciativos da Teoria da Polifonia. Pelo fato de essa fase atual da ANL ter um alcance até mesmo para o exame da linguagem literária, buscou-se, neste artigo, descrever e explicar o sentido do miniconto Os ninguéns. Por meio da unidade de discurso - tripé constituído pela atitude discursiva do locutor, pela Pessoa Enunciativa e pelo conteúdo argumentativo - foi possível explicitar o sentido das entidades linguísticas de modo mais amplo, visto que, examinando enunciação e argumentação, atinge-se, de fato, um estudo mais integral do sistema linguístico e de seu uso no discurso.

Com a análise de Os ninguéns, de Eduardo Galeano, optou-se por descrever o conteúdo argumentativo do discurso, por meio da evocação dos encadeamentos argumentativos que o constituem - à luz da TBS. Em seguida, identificaram-se a atitude discursiva do locutor e a Pessoa Enunciativa, numa tentativa de explicar, de modo mais amplo, o sentido produzido nesse discurso literário. A hipótese inicial de que o conteúdo sendo descrito pela evocação dos encadeamentos argumentativos aprofundaria a explicação semântica - ao invés do método de segmentação dos enunciados confirmou-se, na medida em que não apenas explicitou, com mais clareza, o sentido, mas também deu melhor funcionalidade à análise do corpus. Além 
disso, a quase plena incidência da Pessoa MUNDO mostra, em especial, o fato de o locutor ter-se desresponsabilizado pelo conteúdo por ele introduzido e, na maioria dos casos, posto nesse discurso literário. A única ocorrência de ON indicou a introdução de uma voz da opinião pública, representada, no caso, por crenças da coletividade.

A aplicação dos conceitos teóricos aqui apresentados revela o grande potencial do método de análise semântico-argumentativa proposto pela TAP. Em trabalhos futuros, pretende-se dar continuidade às reflexões iniciadas aqui, buscando examinar, em outros discursos, também o modo de aparição do conteúdo e a atitude do locutor, a partir das noções de primeiro e segundo planos estabelecidas pela função textual.

\section{Referências}

ANSCOMBRE, Jean-Claude; DUCROT, Oswald. L'Argumentation dans la Langue. Bruxelles: Mardaga, 1983.

BALLY, Charles. Linguistique générale et linguistique française. 2. ed. Berne, Suisse: Éditions Francke Berne, 1965.

BERRENDONNER, A. Éléments de pragmatique linguistique. Paris: Editions de Minuit, 1981.

CAREL, Marion. Pourtant: argumentation by exception. Journal of Pragmatics, v. 24, p. 167-188, 1995. <https://doi.org/10.1016/0378-2166(94)00106-0>

CAREL, Marion. Polifonia e argumentação. Desenredo, Revista do Programa de Pós-Graduação em Letras da Universidade de Passo Fundo, v. 6, n. 1, p. 22-36, jan./jun. 2010.

CAREL, Marion. L'Entrelacement argumentatif. Lexique, discours et blocs sémantiques. Paris: Éditions Honoré Champion, 2011.

CAREL, Marion. Introduction. In: CAREL, Marion (Org.). Argumentation et polyphonie: de Saint Augustin à Robbe-Grillet. Paris: L'Harmattan, 2012. p. 7-58.

CAREL, Marion; DUCROT, Oswald. La semántica argumentativa:una introducción a la teoría de los bloques semánticos. Buenos Aires: Colihue, 2005.
CAREL, Marion; DUCROT, Oswald. Atualização da polifonia. Desenredo, Revista do Programa de Pós-Graduação em Letras da Universidade de Passo Fundo, v. 6, n. 1 , p. 9-21, jan./jun. 2010.

CAREL, Marion. Tu serás um homem, meu filho. Um prolongamento da doxa: o paradoxo. Desenredo, Passo Fundo, Ed. da Universidade de Passo Fundo, v. 9, n. 2, p. 254-270, jul./dez. 2013.

DUCROT, Oswald. Les mots du discours. Paris: Les Éditions de Minuit, 1980.

DUCROT, Oswald. Le dire et le dit. Paris: Les Éditions de Minuit, 1984.

DUCROT, Oswald. La polifonía. In: DUCROT, Oswald. Problemas de Lingüística y Enunciación. Buenos Aires: Imprenta de la Faculdad de Filosofía y Letras, 1985.

DUCROT, Oswald. $O$ dizer e o dito. Revisão técnica da tradução Eduardo Guimarães. Campinas, SP: Pontes, 1987.

DUCROT, Oswald. Polifonía y Argumentación. Conferencias del Seminario Teoría de la Argumentación y Análisis del Discurso. Cali: Universidad del Valle, 1990.

DUCROT, Oswald. Os Topoi na "Teoria da Argumentação na Língua". Revista Brasileira de Letras, São Carlos, v. 1, n. 1, p. 1-11, 1999.

DUCROT, Oswald; CAREL, Marion. Descrição argumentativa e descrição polifônica: o caso da negação. Letras de Hoje, Porto Alegre, v. 43, n. 1, p. 7-18, jan./mar., 2008.

DUCROT, Oswald. Argumentação retórica e argumentação lingüística. Letras de Hoje, Porto Alegre, v. 44, n. 1, p. 20-25, jan./mar., 2009.

DUCROT, Oswald. Les risques du discours: Rencontres avec Oswald Ducrot. Propos recueillis par Amir Biglari. Limoges: Éditions Lambert-Lucas, 2013.

GALEANO, Eduardo. O livro dos abraços. 2. ed. Porto Alegre: L\&PM, 2012.

SAUSSURE, Ferdinand de. Curso de Linguística Geral. 7. ed. São Paulo: Cultrix, 1975.

Recebido em 25/09/2017

Aceito em 13/11/2017. 